\title{
From Shared Enaction to Intrinsic Value. How Enactivism Contributes to Environmental Ethics
}

\author{
Konrad Werner $^{1}$ (D) . Magdalena Kiełkowicz-Werner ${ }^{1}$
}

Accepted: 18 May 2021 / Published online: 31 May 2021

(c) The Author(s) 2021

\begin{abstract}
Two major philosophical movements have sought to fundamentally rethink the relationship between humans and their environment(s): environmental ethics and enactivism. Surprisingly, they virtually never refer to or seek inspiration from each other. The goal of this analysis is to bridge the gap. Our main purpose, then, is to address, from the enactivist angle, the conceptual backbone of environmental ethics, namely the concept of intrinsic value. We argue that intrinsic value does indeed exist, yet its "intrinsicality" does not boil down to being independent of the interests and needs of humans. Rather, it is brought forth by what we call shared enaction of an axiological domain. The latter is built upon such core posits of enactivism as autonomy, enaction, participatory sense-making as well as the most recent concept of loving as knowing proposed by Hanne De Jaegher.
\end{abstract}

Keywords Environmental ethics $\cdot$ Enactivism · Intrinsic values $\cdot$ Enaction $\cdot$ Value

Two major philosophical movements have sought to fundamentally rethink the relationship between humans and their environment(s), and to genuinely embed the former in the latter. These two movements are environmental ethics on the one hand, and enactivism - a newly emerging paradigm in cognitive science — on the other. Surprisingly, these movements rarely refer to or seek insight or inspiration from each other.

The goal of this analysis is, firstly, to bridge this gap at least in part; secondly - to demonstrate that building the bridge is worth the effort. We shall be especially interested in the contribution that enactivism can make to environmental ethics.

Our main purpose, then, is to address, from the enactivist angle, the conceptual backbone of environmental ethics as recognized by a number of major thinkers, namely the concept of intrinsic value. We argue that the concept is indeed plausible, yet the "intrinsicality" does not boil down to being independent of the interests and needs of humans. Rather,

Konrad Werner

konrad.t.werner@gmail.com

Magdalena Kiełkowicz-Werner

magdalenakielkowicz@gmail.com

1 University of Warsaw, Faculty of Philosophy, ul. Krakowskie Przedmiescie 3, 00-927 Warszawa, Poland intrinsic value is brought forth by the dynamic of shared enaction, involving a vast number of organisms, including humans, which are fundamentally bonded in dealing with their surrounding and in maintaining their own individual integrity (autonomy).

\section{Enactivism as a Re-conceptualization of the Cognitive Subject}

Enactivism, broadly understood, has become a complex paradigm encompassing a number of internal differences and varying focal points. This presentation of enactivism places at its core the ideas first comprehensively articulated by Varela et al. (1991).

For the sole purposes of this paper, enactivism can be characterized by reference to three ideas; we call them the three turning points or simply the three turns.

\subsection{Embodiment: A Departure from Cognitivism and the Notion of Autonomy}

The first and pivotal turn leads towards the idea of embodiment, and it states that cognition must be a pursuit realized by an actual living creature, a function allowing the creature to maintain its integrity and to survive. Thus enactivism 
(see Rowlands 1999, 2009; Di Paolo 2005; Thompson 2007; Chemero 2009; Di Paolo et al. 2017, 2018) ${ }^{1}$ strongly opposes the idea of cognition defined as abstract computation that might in principle be realized by any appropriately structured system. In other words, enactivism rejects the view according to which the cognitive subject is an abstract information-processing machinery whose connection to the underlying biological and ecological processes is unspecified.

Therefore, living creatures capable of cognition are biological individuals. There is wide-ranging debate on what determines biological individuality (see Pradeu 2011, 2012, 2019; Guay and Pradeu 2016; Godfrey-Smith 2016; Wilson and Barker 2019), but here this notion must be taken for granted. Researchers remotely agree that a biological individual is "a cohesive, relatively well-delineated and often unique entity that remains the'same' through time despite undergoing constant change" (Pradeu 2019, p. 1; pre-print version).

All biological individuals are autonomous systems, which means that they are networks that have the capacity to reproduce themselves (they are autopoietic; see Maturana and Varela 1980), and determine "a domain of possible interactions with the world" (Thompson and Stapleteon 2009, p. 24).

For the sake of this investigation autonomy can be characterized as follows:

(D1) For a given entity to be an autonomous system, the following conditions must be satisfied:

(a) It is realized in a domain called the base of the system.

(b) Its components recursively depend on each other in their (re)production as components of the system.

(c) It is bounded and maintains its boundaries.

(d) It is a unique individual.

(e) It determines a domain of possible interactions with entities that surround the system.

Enactivism stresses that cognition is a way in which a biological individual realizes its autonomy. Cognition belongs to and is produced by the proper functions keeping the autonomous system autonomous (thus, keeping it alive).

Some commentary is in order, however, with respect to the notion of the base (throughout this paper sometimes referred to simply as the world) from D1(a), and thus also the notion of entities that surround the system from point D1(e). Let us emphasize that these notions are not supposed to smuggle in any metaphysical presumption as to

\footnotetext{
${ }^{1}$ Embodiment has also been brought up in a different context by Lakoff (1990) and Johnson (1990).
}

what really exists or the nature of the boundary between the system and its exterior. Yet, we nonetheless need some way of articulating a phenomenological rather than a metaphysical observation that there is something under our feet that is not experienced as being of our own making, but rather as something that comes to us, so to speak. For the worldas-manifested-to-us is something that we find ourselves in, not a projection originating from inside the mind as a sort of "Cartesian theater," to use Dennett's (1991) phrase. As Varela and collaborators put it, we "reflect on a world that is not made, but found, and yet it is also our structure that enables us to reflect upon this world. Thus in reflection we find ourselves in a circle: we are in a world that seems to be there before reflection begins, but that world is not separate from us" (Varela et al. 1991, p. 3).

\subsection{Environment and Action: A Departure from Internalism}

In step with embodiment, the second, ecological turn means that enactivism breaks with the representationalist idea of cognition as an internal machinery, be it computation carried out on internal symbols which are considered causally connected to entities and states in the world (see Dretske 1995; Ramsey 2007), or a machinery of ideas, impressions or sense-data, as posited by Descartes, Locke, Hume or Russell. The point is that positing such internal entities equals advancing something that is decoupled from the external world and for that reason might in principle continue its work even when the external world has ceased to exist.

In contrast, the ecological turn brings up the thesis that the mind is "environmentally plugged-in" (Noë's 2009 phrase). This means that minds or subjects do not only happen to be placed somewhere; instead, they are constituted (made what they are) by this placement, thus by direct interactions with their environments. Here come two of the most pivotal conceptual innovations of enactivism-crucial, if a bridge to environmental ethics is to be erected-namely the notions of sense-making and structural coupling. These establish relationships that make subjects and their environments determine one another.

Speaking of structural coupling and sense-making means that a biological individual "establishes a perspective on the world with its own normativity" (Di Paolo et al. 2010, p. 39).

We propose the following characterization, based on the relevant literature:

(D2) An autonomous system is structurally coupled with its surroundings if:

(a) The system selects some segments of its surrounding, which includes other autonomous systems, and as a result, these entities can be further exploited by the 
system in the process of maintaining its autonomy. This condition is referred to as sense-making, i.e., making the world relevant to the system's capacities and needs.

(b) The selected and/or transformed entities determine future states of the autonomous system. Thus, structural coupling is not a linear process, but rather a looped codetermination of the subject and its surroundings (see Varela et al. 1991, p. 150).

The idea behind the notion of sense-making, as articulated in D2(a), proves crucial when it comes to the problem of a moral relationship with the natural environment, since we cannot think of this environment outside acts of sense-making, but also-crucially, based on D2(b) - we cannot think of ourselves outside these acts (of sensemaking) either.

Based on what has been said, cognition is in principle an activity, i.e., it is constituted by certain actions. This is the third turn. If the biological individual is constituted by structural coupling, then it cannot be conceptualized as a passive recipient of the mere presence of its environment. Instead, it must be engaged in persistent activity, coordinating all sorts of stimuli and thereby navigating, breeding, reproducing, solving problems, etc. This posit constitutes the core tenet of what is at times called sensorimotor enactivism proposed by Noë (2004; see also O'Regan and Noë 2001; Taraborelli and Mossio 2008; De Jesus 2015), which in turn gave rise to radical enactivism championed by Hutto and Myin 2013.

\subsection{The Outcome: Enaction}

According to the traditional, Cartesian view, both the subject and the world are "ready-made," to use Hilary Putnam's (1982) phrase. They are conceived of not only as existing independently of one another, but also as having essential properties that disregard the other side. Enactivism, as qualified by Varela et al. (1991), is a breakthrough in this respect, for "the inevitable conclusion is that knower and known, mind and world, stand in relation to each other through mutual specification and coorigination" (Varela et al. 1991, p. 150). Therefore, the subject is constituted by its embeddedness in the environment, while the environment is constituted by its being coupled with the subject making sense of its surroundings in step with its capacities and needs. Here is Varela and collaborators again, providing a nice metaphor of parachuting:

(...) species brings forth and specifies it own domain of problems to be solved (...); this domain does not exist "out there" in an environment that acts as a landing pad for organisms that somehow drop or parachute into the world (Ibid.: 198).

Therefore, the subject is not a "guest" parachuting into the world, and the world as inhabited by the subject is not merely a pre-given "landing pad." Instead:

(...) cognition is not the representation of a pregiven world by a pregiven mind but is rather the enactment of the world and a mind on the basis of a history of the variety of actions that a being in the world performs (Ibid.: 9)

The crucial thing to emphasize is that enaction, as we pointed out elsewhere (Werner 2020), is productive, which means that a certain realm or domain is brought into being as a relatively robust, stable product of enaction. Hence, what is enacted is not merely relational in a sense similar to the relational character of qualities such as "being taller than" or "being placed on the right side of." Nor is what is enacted secondary in the sense usually attributed to the secondary qualities available in perception which are not considered, at least in the Cartesian tradition, genuine features of reality but mere appearances. In contrast, the enacted realm and thus the enacted entities or qualities are genuine parts of the world. When Varela et al. (1991) say for example that the colored and shaped surfaces of ordinary things are enacted, it should be understood as these surfaces actual coming into being.

Even if the notion of enaction is primitive (thus undefinable) within the enactivist paradigm, it can nonetheless be "represented" by means of different definable concepts. The "representation" we wish to posit draws on the idea, articulated explicitly already by Maturana and Varela (1980), that there are different levels at which autonomous systems can arise. There is certainly the bottom level which, insofar as we can tell, is the level of the biological individual. However, there is no a priori reason to exclude the possibility of higher-level autonomous systems, thus dynamic structures that satisfy the conditions of autonomy. This possibility has been famously exploited in Luhman's (1996) theory of social systems or De Jaegher and Di Paolo's (2007) concept of participatory sense-making.

Here is the way we propose to "represent" the concept of enaction:

(D3) When an autonomous system enacts a domain of its actual and possible interactions, the following conditions are satisfied:

(a) The autonomous system is structurally coupled with a fixed base. 
(b) The autonomous system produces a second-level (higher-order) autonomous system with its domain of structural coupling.

This account has a number of advantages. First, the higher-level autonomous system is determined by a specific base. The enacted realm of our actions, the lifeworld, as Edmund Husserl (1970) called it, cannot therefore be deemed a mere projection of the Cartesian mind, and thus Pascal and O'Regan (2008) are wrong to call Varela's et al. (1991) concept of enaction idealistic: the enacted lifeworld is actually grounded in what is phenomenologically experienced as the realm we find ourselves in.

Second, in D1 the components of autonomous systems are considered responsible for (re)producing the system. When applied to higher-order systems, this notion accounts for the fact that within the cognized (enacted) layout of the world the individual subject's subsequent encounters with its surroundings replicate the same pattern, at times with small changes, to the effect that the entities with which the subject is structurally coupled are taken as extended in space and time, i.e., as "maintaining" their identity.

Third, the enacted realm thought of as a higher-level autonomous system is bounded both externally and internally. Thanks to its external boundaries, what partakes in the system is delineated from what is beyond its scope. The internal boundaries, on the other hand, carve up the patterns of action within the higher-level system. They are "drawn across the board," as Varzi (2016) put it, and as a result of this "drawing" we are faced with the observable divisions between things (called surfaces), events, as well as continuous entities and the discontinuities between them (perceived holes). Varela and collaborators hint at such an account when they write:

How are we to specify (...) edges, boundaries, texture, and orientation, if not in relation to some perceiver for whom these distinctions are relevant? (Varela et al. 1991, p. 167).

Fourthly and finally, the condition referring to structural uniqueness also captures the fact that different kinds of subjects face different presentations of the same world, thus different "drawings" of internal and external boundaries, as determined by their cognitive apparatuses and patterns of structural coupling - thus, at the end of the day, by the unique patterns of autonomy they maintain.

To sum up, the biological (cognitive) subject, making sense of the world in accordance with its capacities and needs, is a bounded creature creating and maintaining selective barriers between its own interior and its surroundings. Yet, unlike in the Cartesian tradition, this subject-world boundary does not signify a metaphysical chasm between two kinds of beings endowed with completely different features-the mind as a thinking substance and the external realm filled with physical stuff. Instead, we should speak a system of context-dependent delineations determined by the conditions of the subject's autonomy, thus by unique patterns of structural coupling and enaction.

That said, enactivism offers a fresh perspective on such notions as objectivity and subjectivity, for the line between them can now be seen as more of an enaction-dependent distinction rather than a fundamental metaphysical chasm between two unbridgeable cliffs. This makes it possible to re-conceptualize the debate over "objective" and "instrumental" values, particularly in environmental ethics which is our major concern here (enactivism, however, is not the only attempt to go beyond the subjective vs. objective dichotomy referring to values; the work of Roman Ingarden 1973, 1983 should especially be mentioned in this context).

\section{Environmental Ethics as a Re-conceptualization of the Realm of Moral Subjects}

From the practical angle, environmental ethics reacts to the devastation of nature primarily as a result of the industrial revolution (see White 1967; Rolston 1989; Jamieson 2001, 2008; Palmer 2002; Callicott and Palmer 2004; Callicott 2013). In this context, environmental ethicists are trying to determine the desirable way to re-relate man to nature (i.e. a way that could change the actual state of affairs). In the next section we shall make the case that enactivism can contribute to this effort, and thus to the expected change in our relationship with nature.

\subsection{Environment-But Which One?}

Some environmental ethicists adopt an alarming tone, clearly separating the human from the non-human for the purposes of protecting the latter from the impact of the former, sometimes even going as far as to condemn the human. For example, Elliot (2001, p. 177) speaks of the human "assault on the terrestrial environment," referring to deforestation, the extinction of species, soil erosion, climate change, to name just a few disastrous phenomena, and then proclaims that "human activity generally leaves its unhappy mark on every part of the biosphere" (ibid.).

However, Dale Jamieson, among others, stresses that the term "environment" does not refer only to the non-human parts of the planet. It also includes human realities, e.g., "Harlem and Brixton" which also count as environments so that the category "includes not just the natural environment, but also the built environment" (Jamieson 2008, p. 1). Therefore, Jamieson claims, a distinction should be made 
between environment and nature. By blending the two we arrive at the notion of natural environment as distinct from human-altered or almost entirely human-built environments. Now, most environmental ethicists are only concerned with the first of these environments.

We are dedicated to making our critical point as straightforward as possible and without further ado. Namely, it seems that targeting the natural environment as clearly distinct from the human-altered environment is an instance of what Varela et al. (1991) figuratively referred to as the "parachuting" subject, where the subject does not really belong to the place where it "lands." Interestingly, this non-belonging is explicitly stated in the famous Wilderness Act of 1964, signed into law by US president Lyndon B. Johnson:

A wilderness, in contrast with those areas where man and his own works dominate the landscape, is hereby recognized as an area where the earth and its community of life are untrammeled by man, where man himself is a visitor who does not remain (Wilderness Act of 1964, p. 1; see also Callicott 1991; Woods 2001)

Therefore, at least at first glimpse, the suggestion is that man is not a genuine part of nature. This is hardly a viable claim now, taking into account what we know about our evolutionary origins, including the origins of our cognitive capacities. Moreover, this axiological separation of the natural from the human seems to be a mirror image of the more traditionalistic dualism between the human and the natural.

The above-mentioned controversy over the concept of nature and the two ways of understanding the notion of environment relates to the main division in environmental ethics which separates anthropocentric conceptions from the rest. Anthropocentric environmental ethics seeks to make the case that the interests of humans should be a constant point of reference in the hierarchy of valuable beings. Hence, the scope of environmental protection is conditioned by human needs.

Non-anthropocentric theories take the opposite point of view. First, they assume that human's privileged position is not legitimate. Second, they advocate conferring moral status on nonhuman beings, regardless of human's interests (see McShane 2007a; Purves 2014). The environment is hailed as possessing intrinsic value. The latter is the main issue to be discussed here.

\subsection{Intrinsic Value: How Come?}

The concept of intrinsic value is at times regarded as "the holy grail of environmental ethics" (Parsons et al. 1993, p. 277), yet there is no full agreement as to how it should be understood (Katz 1987; Callicott 1992, 1995; Lee 1996; O'Neil 1997), and whether or not it is plausible in the first place (Gruen 2002; Elliott 2005; McShane 2007a, b). Here, let us articulate a relatively general characterization: having intrinsic value means being valuable independently of any human action or judgment; independently of the very existence of human beings.

The concept can be illustrated by the famous thought experiment designed by Richard Routley (later Sylvan; see Routley 1973). Routley invited us to imagine a situation in which there is only one man left on Earth. He or she knows that death is unavoidable and has sufficient power to destroy the entire biosphere. Now, the question is, what would prevent the said person from doing so, since it cannot be self-interest (the person will die anyway). If the decision is to be rationally justified, the only rationale for not using destructive powers would be the acknowledgement that the biosphere is in itself worth preserving. Thus it is precisely on grounds of intrinsic value that the biosphere can be said to have an own interest (see e.g., Weston 1996; Morito 2003 or Jamieson 2008 for critical reviews of the argument).

We wish to present an argument which is not directly against the existence of intrinsic value, but rather shows that the concept does not contribute much to what environmental ethics seeks to accomplish.

To begin, let us remind ourselves that the whole experiment, in our understanding, involves an idealized, fully rational subject. That said, there are several options when it comes to the distribution of moral value, so to speak. First, it may be the case that the natural environment has no intrinsic value, thus no moral status when decoupled from what is human. Does it mean that the last man is justified if he decides to destroy it? Yes, but only if the man considers himself as having moral value as a decision maker. Let us keep in mind the rationality condition (as artificial as it is, but it's for the sake of the argument): rational subjects make decisions to do this or that only if they are entitled to do so. Therefore, if the last man has no moral status as one who is entitled to make a decision, and the environment has no moral value either, the only rational option is omission, i.e., doing nothing, abstaining from a decision. Interestingly, when we have a situation in which the environment does have a moral status while the last man still does not, nothing changes - the man still has reasons to consider that he is not entitled to decide.

One particular problem with these scenarios is that when environmental ethicists speak of preserving nature, they have something else in mind, not the rational omission maintaining the status quo. For the status quo, as it is nowadays, is not enough; rather it needs improvement and therefore our actions, not our omissions.

Now, what if in the thought experiment both the last man and the environment had moral standing independently of each other? In this case each particular moral decision involves its own universe of reasons, metaphorically speaking, which means that it depends on the weight of each value 
in the particular case. For when we have two independent values, they may turn out to be in conflict, and there may be a need to order these values, thus to place them on a scale. So, if we take the situation of the last man seriously, it seems, indeed, that there is no conflict, and therefore the last man can rationally decide not to destroy the biosphere. However, what does this tell us about real cases and real-life decisions regarding the interests of man and the interests of the biosphere, when considered as so starkly distinct? Not much.

Therefore, the anthropocentric environmental ethicist can make a good point here: insofar as both nature and humans are valuable independently of each other, every moral decision needs to be deliberated separately. A non-anthropocentric ethicist cannot simply claim that nature has intrinsic value, i.e., that it has moral standing independently of human's judgment, since the only situation in which nature's intrinsic value has direct and automatic consequences for action is the situation of the fictional last man depicted by Routley. Meanwhile in real-life cases the course of action is not always clear. For any course of action requires an assessment of how the intrinsic value of nature tallies with the intrinsic value of human beings. That said, the anthropocentric ethicist, again, can reply that being who we are, i.e., human beings, we will inevitably always prefer a default position that prioritizes human-related values, even if we do concede that nature, too, has intrinsic value. This, however, is not a bitter pill that environmental ethics has to swallow, taking into account the critical need for rethinking man's attitude towards the natural environment, and the latter's dire state.

Therefore, we argue that if a real change in moral thinking is to be expected, it should focus on demonstrating the unity of all organisms engaged in the pursuit of enaction, thus also in the pursuit of valuing, instead of merely recognizing nature's value as a mirror image of the decoupled intrinsic value that humans have for centuries assigned to themselves.

\subsection{Seeking the Right Place for Theoretical Speculations on Value}

One might argue that the concept of intrinsic value is not the holy grail of environmental ethics anymore, or that insofar as it is, it should not be. A thought of this kind was expressed by Norton (2005), who proposes to move towards a less speculative and more practical approach, focusing for example on specific policies. Some thinkers even argue (see e.g. the collection of essays by Light and Katz 1996; Samuelson 2010 for a critical response) that a purely theoretical focus hinders environmental protection (e.g. Maguire and Justus 2008).

In contrast, we assume that the theoretical assumptions spelled out above have very practical consequences, if not for a particular decision, then certainly for a more general way of thinking or conceptualizing the situation that requires a decision to be made. A great example is the issue of conservation policy in the face of natural (or at least not directly man-made) threats that affect strictly protected areas such as the bark beetle outbreak that destroyed wilderness areas in Germany and Poland, among other places. Important examples include the Bavarian Forrest (Müller 2011) and the Bialowieza Forest (Witkowski 2017):

When, despite the strenuous efforts of foresters, the outbreak [in the Bavarian Forest] expanded from the Park to the neighboring tree stands, it turned out that the local community, tourists and forest owners had a different vision of the forest than naturalists from the Park. These people opted for the green forest, not the hectares of dead spruce stands (...). The matter quickly gained political significance. The European Commission, unprepared for solving the problem, commissioned the development of separate procedures for the national park and for commercial forests (Witkowski 2017, p. 351)

What this tells us is that theories have consequences in policy making insofar as they are implicit in the ethical framing of a problem. Therefore, we should not give up theorizing about values (see e.g. Kloor 2015); on the contrary-we believe it is necessary to rethink this framing, including opposite pairs such as natural (wilderness) vs. human-altered; anthropocentric vs. non-anthropocentric; and, at the core of all this, subjective vs. objective. An enactivist intervention, to use Gallagher's (2017) apt phrase, can help in this task.

We share Jamieson's view that the concepts of value "are constructed from acts of evaluation" (Jamieson 2008, p. 75). But we need to ask how this construction is understood: as the disembodied imposition of certain external "measures" on the environment, or as an embodied effort emerging from environmentally plugged-in activity.

\subsection{Prospects for a Non-dualist Theory of Valuing: The Openness of the Subject}

The groundwork informing our idea of enacted value which we are due to set forth later on has been laid by the insightful paper by Greaves and Read (2015). They articulate the idea of an ecology of value characterized by two major theoretical posits: first, values emerge from interactions between at least two living creatures, thus they cannot reside in just one individual; second, values are not things or objects; instead, if articulating their ontological status is of any significance, they are "events" brought forth as part of the processes or interactions between living creatures. We read: 
In this paper we offer an account of valuation that understands values as "residing" neither in a pre-established human realm nor in a pre-established realm of natural beings, but rather in the ongoing encounters whereby the world we reside in comes to be established/maintained as a viable socio-ecological habitat (Greaves and Read 2015, p. 321)

When Greaves and Read put emphasis on the fact that values do not belong to the pre-established realm of human or non-human doing, they are quite in step with the critique of the "parachuting" subject and the "pre-given" world formulated by Varela et al. (1991). Therefore, we understand their proposal as environmental ethics reaching out to enactivism. So the proposal in question lets us get some fresh air after we have found ourselves locked inside the subjective vs. objective and internal vs. instrumental dichotomies prevailing for a long time in the debates on intrinsic value. Here it is, as simple as it gets: the organismic world is in and of itself a wide and extremely complex nexus of valuing processes, with values as "events" partaking in these processes, or "knots" in this nexus.

The central notions that make possible the whole theoretical construct proposed by Greaves and Read (2015) are openness to the world, and its specific, more advanced subtype, namely open-ended openness. Yet rather than being properly defined these notions are illustrated by means of examples.

The first example of openness is perception, thought of as the paradigmatic instantiation of how the subject is sensitive to the world around it, especially to what the world offers him in the form of patterns, opportunities, or cues for action, famously dubbed affordances by Gibson (1979). Another example is desire, which is also inherently, and quite intuitively, connected to valuing.

Once the primitive notion of openness to the world has been set, we are provided with a characterization of openended openness:

While all living beings are open to a range of features and possibilities of the world around them, it is crucial to our argument that ecological valuation requires some beings to inhabit that ecological field that are 'open-endedly open.' That is, beings that are open not only to what the world affords them and their own kind, nor simply open to what the world affords others, such as seeing that a dog uses a chair as a sunshade. Open-endedly open beings are open to an indefinite field of possible encounters that they are not themselves directly involved in (...) (ibid., pp. 322-323)

However, what is lacking in this account of openness, in our assessment, is an explicit reference to cognition. Openness is made possible by cognition, or perhaps even is cognition as such. This bond is clear when we read carefully what Greaves and Read say about living creatures being "open not only to their own world and to the worlds of others, but also to the open-ended potential for possible affordances and encounters between living beings and their worlds" (ibid., p. 328). Open-endedly open beings, they say, "must be beings that understand that there are other open beings" (ibid., p. 329). Unfortunately, the authors do not explain how it comes about that a living being is capable of being open to the world of another creature.

Moreover, the purely relational account of values presented by Greaves and Read (2015) is not sufficient insofar as values are relatively robust, meaning that they do not just show up and disappear when this or that relation of valuing comes about and ceases. Rather, they seem to be products of the relation of valuing. They are brought forth by interactions, but once brought forth they are relatively independent of those interactions. This means that although they would probably cease to exist if all organisms and interactions ceased to exist, the disappearance of this or that specific relationship of valuing does not destroy values as such.

All of these critical points cannot alter the core point, however, namely that in Greaves and Read (2015) we find a bold step towards the idea of values as born of interactions, instead of thinking of them as peculiar residua awaiting "parachuting" subjects. That said, we shall make the case that the notion of enaction is a plausible contribution to the issues outlined above.

\section{Toward the Enacted Value: The Positive Contribution of Enactivism}

\subsection{From Participatory Sense-Making to Shared Enaction}

We shall propose that at the most fundamental level being open to the world means being able to enact the world over the course of shared enaction.

Combining ethical issues with enactivism is not a novel thing in itself. There has recently been a growing number of enactivist works concerned with the origins of affectivity (Colombetti 2007) and normativity, broadly construed, including the seminal paper on participatory sense-making by De Jaegher and Di Paolo (2007) which shall be referred to below (see e.g. McGann 2007; Di Paolo et al. 2010; Barrett 2017). There are also some direct investigations into possible links between enactivism and ethics (Urban 2015). Admittedly, the reference to values and meaning is inherent in the enactivist tradition per se, beginning with Varela et al. (1991), taken further by Weber and Varela (2002; see Barrett 2017 on the difference between the latter work and 
Varela et al. 1991 in this respect), but also harking back e.g. to Jonas (1966).

To begin, it must be noted that the environment of any biological individual, thus of any bottom-level autonomous system, includes, most importantly, other such systems. However, it is not only about structural coupling, as portrayed in D2. For example, predators and prey are structurally coupled with one another. Yet it is not a shared pursuit in the sense of creating something together. The latter bond, i.e., creating something together, is usually better articulated in terms of cooperation. Cooperation can be characterized as "the non-accidental correlation between the behaviours of two or more systems that are in sustained coupling, or have been coupled in the past, or have been coupled to another, common, system. A correlation is a coherence in the behaviour of two or more systems over and above what is expected, given what those systems are capable of doing" (De Jaegher and Di Paolo 2007, p. 490). This shared endeavor has been called participatory sense-making by De Jaegher and Di Paolo (2007). It refers to situations when "regulation of social coupling takes place through coordination of movements," and when "movements-including utterances-are the tools of sense-making." Hence, "coordination affects individual sense-making" and "new domains of social sensemaking can be generated that were not available to each individual on her own" (De Jaegher and Di Paolo 2007, p. 497).

We shall build on the concept of participatory sense making. Yet, there are two reasons why we do not simply employ it as it stands. First, the key feature of the process we wish to postulate here, but not necessarily of participatory sensemaking as proposed by De Jaegher and Di Paolo, is that fact that it is productive in the sense described earlier.

Let us explain this issue in more detail. De Jaegher and Di Paolo emphasize the fact that participatory sense-making is not just any social encounter, but something that must impact the way in which the interactors maintain their autonomy. Moreover, they put forth the crucial posit that an interaction that is constitutive of participatory sense-making "emerges as an entity;" it has "operationally closed organization;" it "constitutes a level of analysis not reducible, in general, to individual behaviors," and therefore enjoys "a temporary form of autonomy" (De Jaegher and Di Paolo 2007, p. 492). As Urban (2015) aptly puts it, autonomous systems "engage in the interactions, but the interaction process can also selforganize and gain an autonomous organization in the domain of relational dynamics" (Urban 2015, p. 124). Our major concern has to do precisely with the concept of temporary autonomy invoked by De Jaegher and Di Paolo. In principle, each form of autonomy is temporary due to life's precariousness (see Jonas 1966), but as it is the case with bottom-level autonomous systems, there must be a structure securing the emergent higher-level (shared) autonomous system just like the boundaries of the organism, among other factors, secure its very existence in a state far from equilibrium and "specify the topological domain of its realization", as Maturana and Varela (1980, p. 79) would say. In other words, participatory sense-making must be a shared "production" of a common, relatively stable and robust realm.

Moreover, while we likely can speak of participatory sense-making already at the level of minimal cognizers in van Dujin's et al. (2006) sense, it is not shared enaction, for it seems too much to say that minimal cognizers such as $E$-coli enact a relatively stable "layout" of their surroundings. That said, the second reason why we build the notion of shared enaction on the concept of participatory sense-making instead of simply employing the latter has to do with a certain rupture in its meaning: it spans the most basic forms of coordination on the one hand and the most complex, productive, social and linguistic behaviors on the other. There is a problematic aspect to it, as we shall see in the next section.

We shall therefore speak here of shared enaction. It is thought of as a productive pursuit grounded in the processes of participatory sense-making. So, shared enaction refers to a situation in which a group of bottom-level autonomous systems coordinate their structural couplings so as to create a shared higher-level autonomous system for the sake of maintaining their individual autonomies. We propose the following:

(D3) When two or more basic-level autonomous systems enact a shared domain (which shall be called shared enaction), the following conditions are satisfied:

(a) Each of the autonomous systems is structurally coupled with its base;

(b) The autonomous systems take part in the joint effort of participatory sense-making;

(c) As a result of the latter, the autonomous systems produce a second-level (higher-order) autonomous system, including these very systems as parts. ${ }^{2}$

(d) Each of the autonomous systems (or at least a sufficient group of them, defined contextually) benefits from the abovementioned production when it comes to the maintenance of its individual autonomy.

Now, we wish to characterize briefly how a certain development of the pursuit of shared enaction leads to the emergence of values. All of the points made below merit separate debate, nonetheless we would like to at least lay the groundwork here.

\footnotetext{
${ }^{2}$ Someone might argue that all instances of enaction are by definition shared enactions. However, this is not that obvious, and it would merit a separate debate.
} 


\subsection{From Shared Enaction to Axiological Systems}

Here we will finally make use of the uniqueness attributable to autonomous systems according to D1(d). To begin, note, however, that this unique individuality is safely negligible at the level of shared enaction and first-order participatory sense-making, as well as in many ordinary-life situations. For example, the differences between unique individuals are completely irrelevant when, for example, a group of animals comes across a river and wants to move ahead. All subjects partaking in the group face remotely the same (species-specific but not individual-specific) situational layout; and all of them have to change their course of action in an organized, coordinated way that is fully determined by environmental factors, in pursuit of maintaining individual autonomyeach one of them has to swim in these circumstances, leaving some space for others, period.

Now, let us expand this initial illustration. Even if the overall course of action is fully determined by environmental factors in the situation just depicted, at least one crucial thing is not determined by them, namely where exactly the river is to be crossed. Suppose that one part of the river is full of stones and multiple mixed currents, which makes it a rather dangerous a place to swim, while a few hundred meters up the river the current becomes steadier. At this point a number of individual differences will likely come to the fore as some members of the group will prefer the riskier but quicker path while others will insist on taking the longer but safer route. Some members of the group will do what they "consider" best for them no matter what, while others will want to follow stronger fellows, etc. Thus some aspects of their unique individualities will play out this time.

Therefore, we can provisionally speak of a specific subtype of the higher-level autonomous system brought forth by shared enaction. For lack of a better phrase, let us dub it the problem domain. However, unlike in the cognitivist tradition, we $d o$ not take problem domains as pre-given realms which must be adequately represented by agents. We take all problem domains as brought forth by shared enaction as the next step in the hierarchy of autonomous systems.

So, the bottom line is this:

(D4) A problem domain (its basic form) arises when a group of autonomous systems must do something as a group in a shared enacted realm, but there is a certain level of flexibility for the individual when it comes to the way in which the expected group behavior is to be realized.

This is the point that most of the attempts to naturalize normativity are predicated on, especially in the fields of ethology and evolutionary psychology (see e.g. Boehm 2012; Tomasello 2016). Some scholars emphasize the role of emotions here, too (e.g. Churchland 2019). In short, according to these views, normativity is produced by the need to coordinate behavior in challenging circumstances.

For the purposes of this paper, we assume that the enactivist solutions are the most promising, hence we won't go any further here and compare them to their representationalist alternatives; that is not our purpose. Instead, we wish to dig deeper into the following problem: enactivism does a good job in explaining how "organisms cast a web of significance on their world" (Di Paolo et al. 2010, p. 39) based on the conditions of their individual autonomy. The organism "is an ontological center that imbues interactions with the environment with significance they do not have in its absence, and this significance is not arbitrary. It is dynamically constructed, and that is the essence of the idea of sense-making" (Ibid., p. 47). However, as we already stated in the previous paragraph, there seems to be a gap between this level of maintaining individual autonomy and the level of sociability and value, i.e. that which genuinely ensures higher-level autonomy.

Let us put this point differently. Di Paolo et al. (2010) define value as "the extent to which a situation affects the viability of a self-sustaining and precarious network of processes that generates an identity" (Di Paolo et al. 2010, p. 48). However, someone might argue that when applied to biological individuals this characterization hints at something closer to valence as the term is used in psychology (see e.g. Shuman et al. 2013), not value. Thus it refers to a basic non-indifference (positiveness or negativeness) of things or events, taken as a means to preserve individual autonomy. But how do values emerge on this basis?

De Jaegher and Di Paolo (2007) stress that there are "degrees of coordination" (Ibid., p. 491) and that coordination "is a ubiquitous phenomenon in physical and biological systems." Therefore, "coordination is typically easily achieved by simple mechanical means and, when cognitive systems are involved, it does not generally require any cognitively sophisticated skill" (Ibid., p. 490). On the other hand, they write that we have to go "beyond a view that defines interaction as simply the spatio-temporal coincidence of two agents that influence each other. We must move towards an understanding of how their history of coordination demarcates the interaction as an identifiable pattern with its own internal structure, and its own role to play in the process of understanding each other and the world" (Ibid., p. 492). Moreover, they also write that a thing "that is not so common in cases of purely physical coupling, but that we find in the social domain, is that patterns of coordination can directly influence the continuing disposition of the individuals involved to sustain or modify their encounter" (Ibid.).

All that being said, the question arises how this more complex level of participatory sense-making and understanding emerges on the basis of "easily achieved" coordination. We argue that there is a qualitative leap between the 
two, for at the level characterized as "the most participatory" (Di Paolo et al. 2010, p. 72) the bond between two individuals becomes "moral," which means that individual autonomy is not a major concern any more (there is no reason to draw a sharp line between humans and other species in this respect, and researchers such as Bekoff and Pierce 2010 have given some examples of justice and sacrifice in non-human animals). So, the question is, how this moral level emerges on the basis of participatory sense-making. Unfortunately, we find no direct answer in De Jaegher and Di Paolo (2007) or in Di Paolo et al. (2010).

To sum up this part, it seems that we can speak of at least two levels of participatory sense-making. There is the relatively effortless first-order participatory sense-making, taking place if not at the level of physical complexes (this claim would likely be going too far) then certainly at the level of minimal cognizers (in the sense of van Duijn et al. 2006 or similar). It is fully determined by, and describable in terms of the maintenance of individual autonomies. In other words, it is a shared endeavor whose sole purpose is to contribute to individual autonomies. In addition, we propose that there is a level of higher-order participatory sense-making involving a certain specific disposition, as De Jaegher and Di Paolo (2007) call it—perhaps the "openness" investigated by Greaves and Read (2015). And yet the latter is hardly describable solely in terms of individual autonomies.

All that being said, in order to make further steps we would like to reference another contribution by De Jaegher-her most recent (2019) work. First, however, it should be noted that while most of our investigations so far have been affected first of all by the embodiment condition as characterized in 1.1, cashed out in terms of individual autonomy, in order to transcend this individual level and move towards the domain in which valuing the other becomes possible it is necessary to adopt the action-based approach briefly mentioned in 1.3. The point is that even the most sophisticated cognitive endeavors are in principle based on things we do with our bodies in our environment (see also Di Paolo et al. 2018).

Now, when it comes to the shift from the fixation on individual autonomy to genuine interest in the other, we argue that it must be, indeed, a move - thus that the change in focus is predicated on a specific activity, a special thing we do. As simplistic as it may sound at first-it is letting the other $d o$ the things they do without pre-determining these. We are referring here to what De Jaegher (2019) dubs loving as knowing, which, aside from the concept of participatory sense-making, draws inspiration from Kym Maclaren's (2002) conception of "knowing as letting be."

The "letting be" part is an apt expression of the familiar fact that each act of getting to know something unpacks and thus determines some aspects of the known thing (e.g., in a description), but can never exhaust it, meaning that in each particular act of knowing there is always something left undetermined. We read:

In the engagement of knowing, the processes, events and beings that the knower knows balance between being themselves and being-as-they-are-known. That is: they are determined in part by themselves (their own being) and in part by the knower's being (her situation, motivations, interests). They are never fully selfdetermined, and never fully other-determined-always dialectically evolving between determinations.

This is what letting be is: an ongoing, moving, dialectical balancing between the being of the knower (who lets be) and the being of the known (...) (De Jaegher 2019, p. 13; quoted from the published pre-print version).

It is not clear what range of beings can actually be known in this manner, but certainly knowing other subjects belongs there. To capture this specific case, thus when knowing as letting be applies to inter-subjective relations and combines with participatory sense making, De Jaegher (2019) coins the catchy notion of loving as knowing. In her view, the subjects "are personally implicated" in the relation of loving and "need to deal with the double-sided risks of determination. They need to deal both with being-determined (by the other, by the relation, and by themselves) and with determining (the other, the relation, and themselves)" (ibid., p. 15). It is a "continual, ongoing balancing act between too much and too little determination between the knower (who lets be) and the known (who is being let be)" (ibid.). Thus loving is the knowing as letting be as played out between subjects.

We take the loving relationship in a somewhat "technical" sense here, meaning that it refers to a specific kind of internal dynamics within a group of individuals, such that overdetermination by strict norms would impede the pursuit of finding a viable group solution to whatever problem the group faces. Instead, underdetermination, thus giving the subjects some amount of freedom in their attempts to deal with the problem, may be beneficial for achieving the greater goal of ending up with a viable group solution. ${ }^{3}$

Someone might ask what it is that renders the idea of loving as letting be an especially good fit for the activity-based approach within the enactivist paradigm, and, most importantly, how it contributes to the story told above, explaining the emergence of values. In response, we would like to note two things. First, as clearly indicated above, letting be comes on stage, so to speak, as part of embodied problem solving,

\footnotetext{
${ }^{3}$ It should also be remembered that the concept of love has its established place in the autopoietic tradition, as already exemplified by Maturana and Varela (1980), but first of all by Maturana and VerdenZöller (2008).
} 
thus problem solving that consists of actually doing things in the environment, likely including some transformations thereof, not internal representational computation. Hence, loving is doing, which is especially clear if we investigate its likely evolutionary origin. Here we refer to the final part of Di Paolo's et al. (2010) paper, the part which the authors themselves characterize as the most speculative, in which they reflect on the capacity to play-in humans and in some other species-attributable to infants specifically, though not exclusively (see Schwartzman 1978; Fagen 1981). The core of playing is doing things, e.g. when kids play different roles (a mother, a child, a king or a cowboy). Whatever the content of a role, the role must be performed. Now, although there is no place here to discuss it in detail, we would like to flag the idea that it is precisely in playing that subjects learn not to over-determine the other; thus, to let other be and $d o$. Another pregnant concept that comes up in this context, also based on doing things, is trust. Letting be requires trust, but, on the other hand, it also opens room for trust. Where else could trust emerge if not in the realm of doing things? The point is, therefore, that it is precisely the capacity of letting the other be-which is a genuine activity - that enables us not to get stuck with individual autonomy only, but to move beyond the individualist approach towards the properly social domain.

Addressing the second concern raised above, referring to the applicability of the concept of loving as knowing to the problems discussed in this paper, as we have mentioned, there might be situations in which coordinating individual behaviors is not sufficient to solve a problem. Therefore, provided that the relevant environmental conditions allow it (e.g., there is no need to act in a split second), the group may develop a further, even more complex, and more timeconsuming and cognitively demanding strategy of solving the problem. This latter strategy would be such that, unlike in the scenario of mere coordination, the individual actions directed towards a solution are selectively left free, undetermined. This would be a strategy of selected "letting be" in Maclaren's (2002) and De Jaegher's (2019) sense, this time referring to individual actions. So, loving as knowing, resp. loving as letting be, resp. loving as doing is here deemed a crucial contribution to solving complex problems.

The said contribution of letting be to problem solving is a well-recognized phenomenon, yet named differently e.g. in theory of management (Bilton 2007). Yet, the latter assumes what we wish to problematize here explicitly, namely the fact that in order to make such an underdetermined system of thinking, problem solving and decision making possible and viable, there must be a very special bond between the agents taking part in it-the one "technically" called loving as knowing here.

Finally, and crucially for us, there must be a relatively stable structure produced by loving as knowing which in turn makes it possible for loving to re-produce within the system. This specific realm, combining underdetermination with coordination we call here an axiological domain. The intuition is clear: if norms or rules brought forth by coordination of behavior do not fully determine what the individual subjects are supposed to do to solve a complex problem in their environment, then we need to look for higher-level factors, something more than coordination, if we are to account for the complex balancing between underdetermination and overdetermination. The point is, we argue, that in this context we need to speak of values.

The dialectical bond between the relationship of loving as knowing and values as the products and ingredients of shared enaction has not been addressed by De Jaegher (2019) though. It would merit a whole new paper, but let us only flag the open-ended nature of this dialectic. On the one hand, referring to loving signifies that the pursuit so referenced is grounded at least in large part in our emotionality. Therefore, the proper conclusion is that there is no value without experiencing the world in a very specific way, one that is not exhibited by all living creatures, but certainly by some, and certainly not only by humans. On the other hand, the relationship of loving as knowing, thus letting our fellow subjects be who they are-provided it is not dependent on momentary moods and short-lived outpourings of emotion-must be grounded in recognizing the loved and the known as being of value. Thus they must be recognized as parts of a relatively stable structure produced by shared enaction. For otherwise what would be the rationale for letting them be what they are?

To detach the loving as knowing relationship from fluctuating moods, it must be thought of as part of shared enaction, thus - as we have stressed many times in this paper-as part of the productive effort of establishing a relatively stable higher-order autonomous system. That being said, values can be thought of as those "axes" of the produced structure that are precisely the products of loving as knowing. In other words, in real-life cases shared enaction as a complex endeavor can hardly be decomposed into separate currents, but we can at least theoretically "distill" its elements, and values would be the elements that are brought forth thanks to the contribution of the loving as knowing bond. So, in short: values are products of loving as knowing and in turn, in an open-ended manner, provide a stable ground for the loving as knowing bond.

To sum up, we therefore propose:

(D5) An axiological domain is a relatively stable realm, a higher-level autonomous system brought forth by shared enaction involving systems that are capable of solving complex problems in their environments by implementing the letting be strategy. The latter is possible due to a very specific bond called loving as knowing. The core feature 
of this realm is the fact that the individuals are able to deal with what de Jaegher (2019) refers to as balancing between underdetermination and overdetermination.

(D6) Speaking of values refers to relatively stable patterns of the balancing cited above.

Noteworthily, the emergence of the axiological domain should not be interpreted as the rise of a specific setup of values such that there is an axiological domain of one group of subjects and a different axiological domain of a different group. Our point is that loving as letting be gives rise to the axiological domain as such, the latter being a space in which different systems of values coexist or compete. The axiological domain is a realm in which different values are made possible in the first place.

This approach enables us to capture some significant features that we usually attribute to axiological realms and to values themselves as their ingredients:

Firstly, the axiological domain is not decoupled from its base, while at the same time, as a higher-level autonomous system, it cannot be reduced to the base (so, while being naturalist in spirit, our account goes against the view that values are epiphenomenal byproducts).

Secondly, and most importantly, all entities engaged in the production of an axiological higher-level autonomous system owe their status as parts of the axiological system to that system as a whole, while at the same time re-producing the system and themselves as components of the system (one could say that they re-affirm one another as members of the axiological stratum of the world; as valuable entities).

This constant, ongoing self-re-production gives rise to what may be referred to as the objectivity of values: values are objective in the sense that they are not merely accidental outcomes of individual valuing, and they are not momentary, but instead they are relatively stable products of intersubjective pursuits of shared enaction. Assuming the productivity of enaction, once they are enacted they exist as all other products of enaction do; no less objectively than all the other elements of the cognized layout of reality, including the surfaces of things we encounter every day.

Now the core claim underlying the effort of environmental ethics can be given a new formulation: the range of bottom-level autonomous systems partaking in the shared enaction of axiological domains is broader than the set of human beings and includes many other species. In a stronger formulation, one might claim that the whole biosphere is an axiological domain due to the extremely complex interconnectedness of all its constituents.

Two comments are in order, however. First, the proposed view is overtly melioristic, meaning that the values which emerge on the basis of loving as letting be are in principle supposed to be positive. That said, more work needs to be done to account for any negative values or disvalues that emerge. The latter must in some way parasitize on the positive values.

Another limitation of the proposed approach is that it subordinates the value of non-organic parts of the environment to the value of living creatures. ${ }^{4}$ That said, more work needs to be done to provide a more detailed account of how values attributed e.g. to rocks and water emerge, but certainly we don't want to leave the reader with the impression that nonorganic nature is left out of the picture.

\section{Conclusion: Axiological Systems are, Indeed, intrinsically Valuable}

In this concluding section we return to the problem of intrinsic value. Here is the crux of our proposal: natural environments, including human beings, are indeed axiological domains. The axiological layer, so to speak, has emerged gradually over the course of evolution. For example, it is a well known phenomenon that mammals and birds are capable of highly complex coordinated behaviors such as migration or cooperative hunting, but also extensive care in the course of a relatively long process of growing up. They are also capable — let us not forget about it — of play. Meanwhile, care and play seem to necessary engage the letting be relationship (see Urban 2015 on the former and Di Paolo et al. 2010 on the latter).

Now, even if an anthropocentric thinker would insist that the proper axiological domain was brought forth by the emergence of humans, this does not change the fact that it was an outcome of multiple evolutionary processes, and as such it would not have come about without the evolutionary pattern built into it.

Our view cannot be called anthropocentric because it is definitely not the case that within an axiological domain everything is subordinate to the needs and interests of humans; the axiological domains conceived of as higher-level autonomous systems simply do not work this way. Any attempt to force this kind of subordination would ruin the subtle internal dynamic of the shared, environmentally pluggedin enaction of values. Perhaps someone would argue that this ruin is exactly what happened at some point, and thus that humans decided to sign out of the axiological domain, thereby rendering themselves "visitors" in the natural environment. This belief does not seem unreasonable to us, but the right solution in this case would be to attempt to rebuild the ruined domain with humans included in it, instead of

\footnotetext{
${ }^{4}$ Both of these issues, the problem of disvalues and the question of the value of non-organic nature have been raised by an anonymous reviewer of this paper, to whom we are very grateful.
} 
targeting them as genuine "parachuters" and aggressors who cannot be re-socialized by any means.

As for the latter, one thing needs to be made clear. If humans are to be re-introduced into the axiological domain, the irreversibility of the negative impact of axiological separation needs to be acknowledged. There is no way back to the state of the world from the periods predating the separation. What we have done to planet Earth will persist. Enactivism provides the tools to apprehend, understand and in a sense accept this fact due to its inherent tendency to emphasize looped rather than linear processes. Man's impact on the environment also creates a loop. The environment shaped us, we re-shaped the environment, and this in turn re-shaped us. The point is that we are now morally obliged not to try to find a way back, which would be in vain, but to bring forth one more loop, this time more beneficial instead of destructive and exploitative.

Finally, what about the intrinsic value of nature? If the natural environment is in itself a higher-level axiological autonomous system, then it is intrinsically valuable, thus the critical condition emphasized by those who argue in support of intrinsic value is satisfied-the values of different parts of the system are never subordinate to the needs and interests of just one constituent; thus it is not the case the values attributable to, say, animals living in rain forests are subordinate to the interests of men living in their neighborhood.

Note, however, that a shift can now be traced in the meaning of the word "intrinsic." It can now be said that the environment, including both human-altered urban and agricultural areas as well as less human-altered and, most preciously, unaltered wildlife areas has an intrinsic value. However, this time it means that the value is produced by the internal (to the system) nexus of structural couplings and shared enactions populated by many different species, including humans (we can discuss to what extent our position is exceptional or significant in practice, but it will always be exceptional to some extent and in some respects), some of which are engaged in the production of axiological higher-level autonomous systems. Nevertheless, the values are not intrinsic in the sense of being opposed to man allegedly standing outside of nature.

Funding Magdalena Kielkowicz-Werner's research was supported by the National Science Centre in Poland (Narodowe Centrum Nauki), grant no 2016/21/N/HS1/03491.

Open Access This article is licensed under a Creative Commons Attribution 4.0 International License, which permits use, sharing, adaptation, distribution and reproduction in any medium or format, as long as you give appropriate credit to the original author(s) and the source, provide a link to the Creative Commons licence, and indicate if changes were made. The images or other third party material in this article are included in the article's Creative Commons licence, unless indicated otherwise in a credit line to the material. If material is not included in the article's Creative Commons licence and your intended use is not permitted by statutory regulation or exceeds the permitted use, you will need to obtain permission directly from the copyright holder. To view a copy of this licence, visit http://creativecommons.org/licenses/by/4.0/.

\section{References}

Barrett NF (2017) The normative turn in enactive theory: an examination of its roots and implications. Topoi 36:431-443

Bekoff M, Pierce J (2010) Wild justice: the moral lives of animals. The University of Chicago Press, Chicago

Bilton C (2007) Management and creativity: from creative industries to creative management. Blackwell, Oxford

Boehm C (2012) Moral origins: the evolution of virtue, altruism, and shame. Basic Books, New York

Callicot JB (1992) Rolston on intrinsic value: a deconstruction. Environ Ethics 14(2):129-143

Callicott JB (1991) The wilderness idea revisited: the sustainable development alternative. In: Callicott JB, Nelson MP (eds) The great new wilderness debate. University of Georgia Press, Athens, pp 337-366

Callicott JB (1995) Intrinsic value in nature: a metaethical analysis. Electron J Anal Philos 3(5):1-8

Callicott JB (2013) Thinking like a planet: the land ethic and earth ethic. Oxford University Press, Oxford

Callicott JB, Palmer C (eds) (2004) Environmental philosophy: critical concepts in the environment. Routledge, London

Chemero A (2009) Radical embodied cognitive science. The MIT Press, Cambridge

Churchland PS (2019) Conscience: the origins of moral intuition. W. W Norton \& Company, New York \& London

Colombetti G (2007) Enactive appraisal. Phenomenol Cogn Sci 6:527-546

De Jaegher H (2019) Loving and knowing: reflections for an engaged epistemology. Phenomenol Cogn Sci. https://doi.org/10.1007/ s11097-019-09634-5

De Jesus P (2015) Autopoietic enactivism, phenomenology and the deep continuity between life and mind. Phenomenol Cogn Sci 15:265-289

De Jaegher H, Di Paolo E (2007) Participatory sense-making: an enactive approach to social cognition. Phenomenol Cogn Sci 6(4):485-507

Dennett D (1991) Consciousness explained. Little, Brown and Co, New York

Di Paolo EA (2005) Autopoiesis, adaptivity, teleology, agency. Phenomenol Cogn Sci 4(4):429-452

Di Paolo EA, Rohde M, De Jaegher H (2010) Horizons for the enactive mind: values, social interaction, and play. In: Stewart J, Gapenne O, Di Paolo E (eds) Enaction: toward a new paradigm for cognitive science. MIT Press, Cambridge, pp 33-88

Di Paolo E, Buhrmann T, Barandiaran X (2017) Sensorimotor life. An enactive proposal. Oxford University Press, Oxford

Di Paolo E, Cuffari EC, De Jaegher H (2018) Linguistic bodies: the continuity between life and language. MIT Press, Cambridge

Dretske F (1995) Naturalizing mind. MIT Press, Cambridge

Elliot R (2001) Normative ethics. In: Jamieson D (ed) A companion to environmental philosophy. Blackwell, Oxford, pp 177-191

Elliot R (2005) Instrumental value in nature as a basis for the intrinsic value of nature as a whole. Environ Ethics 27(1):43-56

Fagen R (1981) Animal play behavior. Oxford University Press, Oxford Gallagher S (2017) Enactivist interventions: rethinking the mind. Oxford University Press, Oxford 
Gibson JJ (1979) The ecological approach to visual perception. Houghton Mifflin, Boston

Godfrey-Smith P (2016) Individuality, subjectivity, and minimal cognition. Biol Philos 31(6):775-796

Greaves T, Read R (2015) Where value resides: making ecological values possible. Environ Ethics 37:321-340

Gruen L (2002) Refocusing environmental ethics: from intrinsic value to endorsable valuations. Philos Geogr 5(2):153-164

Guay A, Pradeu T (eds) (2016) Individuals across the sciences. Oxford University Press, Oxford. https://doi.org/10.1093/acprof:oso/ 9780199382514.001.0001

Husserl E (1970) The crisis of european sciences and transcendental phenomenology. Northwestern University Press, Evanston

Hutto D, Myin E (2013) Radicalizing enactivism: basic minds without content. MIT Press, Cambridge

Ingarden R (1973) The literary work of art. Northwestern University Press, Evanston, IL

Ingarden R (1983) Man and value. Philosophia Verlag, München

Jamieson D (ed) (2001) A companion to environmental philosophy. Blackwell, Oxford

Jamieson D (2008) Ethics and the environment: an introduction. Cambridge University Press, Cambridge

Johnson M (1990) The body in the mind: the bodily basis of meaning, imagination, and reason. University of Chicago Press, Chicago

Jonas H (1966) The phenomenon of life: toward a philosophy of biology. Northwestern University Press, Evanston

Katz E (1987) Searching for intrinsic value: pragmatism and despair in environmental ethics. Environ Ethics 9(3):231-241

Kloor K (2015) The battle for the soul of conservation science. Issues Sci Technol 31(2):73-79

Lakoff G (1990) Women, fire and dangerous things: what categories reveal about the mind. University of Chicago Press, Chicago

Lee K (1996) The source and locus of intrinsic value: a reexamination. Environ Ethics 18(3):297-309

Light A, Katz E (eds) (1996) Environmental pragmatism. Routledge, London

Luhman N (1996) Social systems. Stanford University Press, Stanford

Maclaren K (2002) Intercorporeality, intersubjectivity and the problem of 'letting others be.' Chiasmi Int 4:187-210

Maguire LA, Justus J (2008) Why intrinsic value is a poor basis for conservation decisions. Bioscience 58(10):910-911

Maturana H, Varela F (1980) Autopoiesis and cognition: the realization of the living. Kluwer, Dordrecht

Maturana-Romesín H, Verden-Zöller G (2008) The origin of humanness in the biology of love. Imprint, Exeter

McGann M (2007) Enactive theorists do it on purpose: toward an enactive account of goals and goal-directedness. Phenomenol Cogn Sci 6:463-483

McShane K (2007a) Why environmental ethics shouldn't give up on intrinsic value. Environ Ethics 29(1):43-61

McShane K (2007) Anthropocentrism vs. nonanthropocentrism: why should we care? Environ Values 16(2):169-85

Morito B (2003) Intrinsic value: a modern albatross for the ecological approach. Environ Values 12:317-336

Müller M (2011) How natural disturbance triggers political conflict: bark beetles and the meaning of landscape in the Bavarian Forest. Global Environ Change 21(3):935-946

Noë A (2004) Action in perception. MIT Press, Cambridge

Noë A (2009) Out of our heads: why you are not your brain, and other lessons from the biology of consciousness. Hill and Wang, New York

Norton BC (2005) Sustainablity: a philosophy of adaptive ecosystem managment. The University of Chicago Press, Chicago

O'Regan S, Noë A (2001) A sensorimotor account of vision and visual consciousness. Behav Brain Sci 24(5):939-973
O’Neil R (1997) Intrinsic value, moral standing, and species. Environ Ethics 19(1):45-52

Palmer C (2002) An overview of environmental ethics. In: Light A, Rolston H III (eds) Environmental ethics: an anthology. Blackwell, Oxford

Parsons R, Daniel TC, Tassinary LG (1993) Landscape aesthetics, ecology, and human health. in defense of instrumental values. In: Covington W (ed) Sustainable ecological systems. USDA Forest Service, Ft. Collins, pp 266-280

Pascal FP, O'Regan JK (2008) Commentary On Mossio and Taraborelli: is the enactive approach really sensorimotor? Conscious Cogn 17(4):1341-1342

Pradeu T (2011) A mixed self: the role of symbiosis in development. Biol Theory 6(1):80-88

Pradeu T (2012) The limits of the self: immunology and biological identity. Oxford University Press, New York

Pradeu T (2019). Immunology and Individuality e-life. https://doi.org/ $10.7554 /$ eLife. 47384

Purves D (2014) Anthropocentric indirect arguments and anthropocentric moral attitudes. Ethics Policy Environ 17(3):267-270

Putnam H (1982) Why there isn't a ready-made world. Synthese 51(2):141-167

Ramsey WM (2007) Representation reconsidered. Cambridge University Press, Cambridge

Rolston H III (1989) Environmental ethics: duties to and values in the natural world. Temple University Press, Philadelphia

Routley R (1973) Is there a need for a new, an environmental ethic?. In: Proceedings of the 15th world congress of philosophy, vol 1. pp 205-210.

Rowlands M (1999) The body in mind: understanding cognitive processes. Cambridge University Press, Cambridge

Rowlands M (2009) Enactivism and the extended mind. Topoi 28(1):53-62

Samuelson L (2010) Environmental pragmatism and environmental philosophy: a bad marriage! Environ Ethics 32(4):405-415

Schwartzman HB (1978) Transformations: the anthropology of children's of play. Plenum, New York

Shuman V, Sander D, Scherer KR (2013) Levels of valence. Front Psychol. https://doi.org/10.3389/fpsyg.2013.00261

Taraborelli D, Mossio M (2008) On the relation between the enactive and the sensorimotor approach to perception. Conscious Cogn 17(4):1343-1344

Thompson E (2007) Mind in life: biology, phenomenology, and the sciences of mind. Harvard University Press, Cambridge

Thompson E, Stapleteon M (2009) Making sense of sense-making: reflections on enactive and extended mind theories. Topoi 28(1):23-30

Tomasello M (2016) The natural history of human morality. Harvard University Press, Cambridge

Urban P (2015) Enactivism and care ethics: merging perspectives. Filozofia 70(2):119-129

van Duijn M, Keijzer F, Franken D (2006) Principles of minimal cognition: casting cognition as sensorimotor coordination. Adapt Behav 14(2):157-170

Varela F, Thompson E, Rosch E (1991) The embodied mind: cognitive science and human experience. MIT Press, Cambridge

Varzi A (2016) On drawing lines across the board. In: Zaibert L (ed) The theory and practice of ontology. Palgrave Macmillian, London, pp 45-78

Weber A, Varela F (2002) Life after Kant: natural purposes and the autopoietic foundations of biological individuality. Phenomenol Cogn Sci 1(2):97-125

Werner K (2020) Enactment and construction of the cognitive niche: toward an ontology of the mind-world connection. Synthese 197(3):1313-1341. https://doi.org/10.1007/s11229-018-1756-1 
Weston A (1996) Beyond intrinsic value: pragmatism in environmental ethics. In: Light A, Katz E (eds) Environmental pragmatism. Routledge, London, pp 285-306

White L (1967) The historical roots of our ecologic crisis. Science 155:1203-1207

Wilderness Act of 1964 Public Law 88-577 (16 U.S. C. 1131-1136) 88 Congress, second session 3 Sep 1964. Available online: https:// winapps.umt.edu/winapps/media2/wilderness/NWPS/documents/ publiclaws/PDF/16_USC_1131-1136.pdf

Wilson RA, Barker MJ (2019) Biological individuals. In: Zalta E (ed) The stanford encyclopedia of philosophy (Fall 2019 Edition) https://plato.stanford.edu/archives/fall2019/entries/biology-indiv idual/. Accessed 18 Nov 2019
Witkowski Z (2017) The Bialowieza Forest controversy in the light of the world dispute in conservation biology. For Res Pap 78(4):347-356

Woods M (2001) Wilderness. In: Jamieson D (ed) A companion to environmental philosophy. Blackwell, Oxford, pp 349-361

Publisher's Note Springer Nature remains neutral with regard to jurisdictional claims in published maps and institutional affiliations. 